\title{
Aerodynamic benefits for a cyclist by drafting behind a motorcycle
}

\author{
Bert Blocken $^{1,2}$ (D) Fabio Malizia ${ }^{1,2} \cdot$ Thijs van Druenen $^{1} \cdot$ Stefanie Gillmeier $^{1}$
}

Published online: 22 September 2020

(c) The Author(s) 2020

\begin{abstract}
Motorcycles are present in cycling races for reasons including television broadcasting. During parts of the race, these motorcycles ride in front of individual or groups of cyclists. Concerns have been expressed in the professional cycling community that these motorcycles can provide aerodynamic benefits in terms of drag reduction for the cyclists drafting behind them. However, to the best of our knowledge, no information about the extent of these benefits is present in the scientific literature. Therefore, this paper analyses the potential drag reduction for a cyclist by drafting behind a motorcycle. Wind tunnel measurements and numerical simulations with computational fluid dynamics were performed. It was shown that drafting at separation distances $d=2.64,10,30$ and $50 \mathrm{~m}$ can reduce the drag of the cyclist down to $52,77,88$ and $93 \%$ of that of an isolated cyclist, respectively. A cyclist power model is used to convert these drag reductions into potential time gains. For a non-drafting cyclist at a speed of $54 \mathrm{~km} / \mathrm{h}$ on level road in calm weather, the time gains by drafting at $d=2.64,10,30$ and $50 \mathrm{~m}$ are 12.7, 5.4, 2.7 and $1.6 \mathrm{~s}$ per km, respectively. These time differences can influence the outcome of cycling races. The current rules of the International Cycling Union do not prevent these aerodynamic benefits from occurring in races.
\end{abstract}

Keywords Computational fluid dynamics $\cdot$ Wind tunnel $\cdot$ Aerodynamic cyclist drag $\cdot$ Cycling aerodynamics $\cdot$ motorbike

\section{Introduction}

At racing speeds of about $40 \mathrm{~km} / \mathrm{h}$, the aerodynamic resistance or drag of a cyclist is about $90 \%$ of the total resistance [1-3]. Therefore many efforts in professional cycling and in cycling research are focused on the reduction of the cyclist's drag. Especially in the past two decades, scientific research in cycling aerodynamics has rapidly increased as reported in recent review papers [4, 5]. Recent research has focused on the factors determining the aerodynamic resistance, including different cyclist positions (e.g. [6-11]) and the associated flow topologies [12-14], the bicycle and bicycle components

Electronic supplementary material The online version of this article (https://doi.org/10.1007/s12283-020-00332-z) contains supplementary material, which is available to authorized users.

Bert Blocken

b.j.e.blocken@tue.nl

1 Building Physics and Services, Department of the Built Environment, Eindhoven University of Technology, P.O. Box 513, 5600 MB Eindhoven, The Netherlands

2 Building Physics Section, Department of Civil Engineering, KU Leuven, Kasteelpark Arenberg 40, Bus 2447, 3001 Leuven, Belgium
[5, 15-17], wearable equipment such as helmets (e.g. [18, 19]) and the interaction between drafting cyclists [20-25]. Together with previous studies, these efforts have led to more and better insights in the aerodynamics of cycling.

Less attention however has been given to the aerodynamic interaction between cyclists and in-race vehicles. Cycling races contain a multitude of cars and motorcycles. The latter are present for various purposes: neutral support, commissaire activities, traffic managing, information provision, doctor and police duties and press, where the latter can be camera, sound or photographer crews. While cars generally stay behind the cyclists, motorcycles are allowed to maneuver in the proximity of the cyclists when filming or recording, and filming is only forbidden in the last $500 \mathrm{~m}$ of the race. Blocken and Toparlar [26] demonstrated that a team car following a cyclist can yield a drag reduction for the cyclist of 3.7, 1.4 and $0.2 \%$ for separation distances of 3,5 and $10 \mathrm{~m}$, respectively. Blocken et al. [27] assessed that a motorcycle following a cyclist can provide a drag reduction for the cyclist of 3.8, 0.3 and $0.1 \%$ for separation distances of 1,5 and $10 \mathrm{~m}$, respectively. These benefits were attributed to the upstream effect that a moving vehicle exerts on the flow around it. 
While it could be argued that this upstream effect was more relevant and novel from a scientific point of view, however, in terms of practical relevance, the largest aerodynamic benefits are expected when a cyclist is drafting not before, but behind a motorcycle. Indeed, it is well-known in the cycling community that drafting behind another cyclist or a vehicle can yield a large drag reduction. This situation is relevant because unavoidably, during parts of the race, some of the motorcycles will ride in front of individual or groups of cyclists and these cyclists can exploit the drafting benefits, leading to an unfair advantage over their opponents. Examples of different situations in races are shown in Fig. 1. The relevant guidelines of the International Cycling Union (UCI) for "vehicle circulation in the race convoy" only stipulate when and which motorcycles can enter the gaps between breakaway riders and the following riders in terms of time differences, which can be 15, 30, 60 and $90 \mathrm{~s}$ [28]. The larger the time differences, the more motorcycles can enter the gap. However, the UCI guidelines do not specify what distance should be kept between the motorcycles and the cyclists behind them.

Drafting of cyclists behind motorcycles is common in races. Cyclists have a tendency to position themselves behind the motorcycle to reduce their drag (Fig. 1a, c). Moreover, sometimes the roads are so narrow that they are
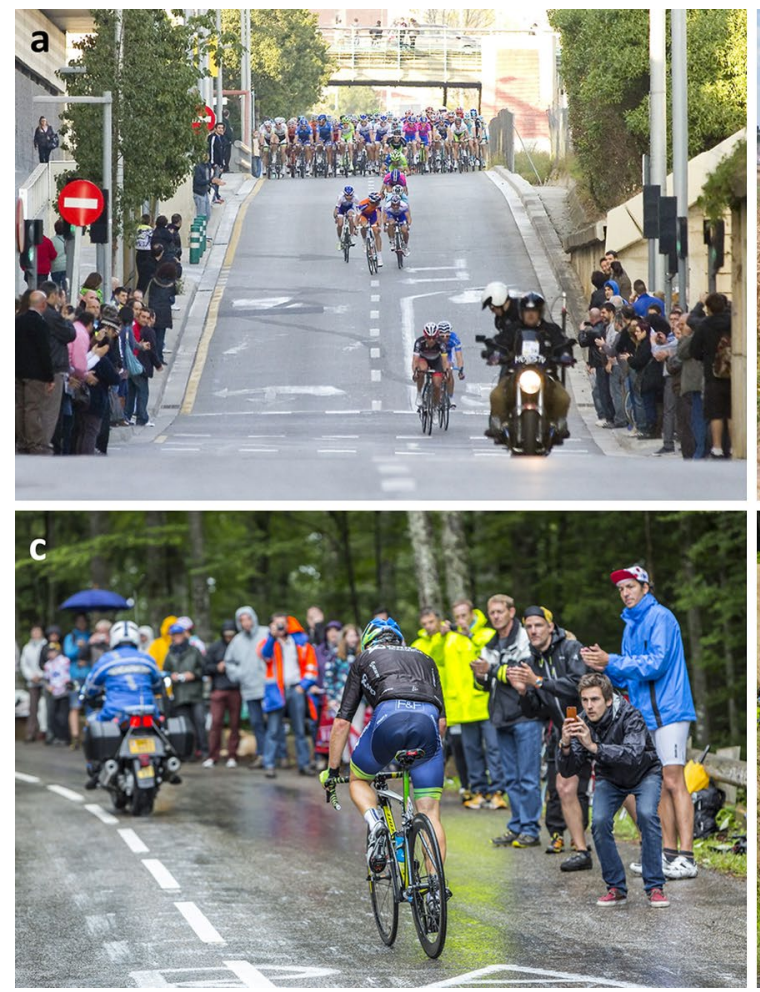

Fig. 1 Photos indicating drafting behind a motorcycle in different types of situations: a wide undulating road; $\mathbf{b}$ narrow level road; $\mathbf{c}$ upward sloped road; d narrow uphill road. (Fig. sources: a Natur- forced to ride behind the motorcycle (Fig. 1b, d). Because this happens frequently, concerns have been expressed in the professional cycling community that these aerodynamic benefits can influence the outcome of the race [29, 30]. However, to the best of our knowledge, there is no information in the scientific literature about the drag reduction for a cyclist by drafting behind a motorcycle. Therefore, this paper presents an analysis to assess these drag reductions for a range of separation distances between cyclist and motorcycle.

\section{Wind tunnel experiments}

Quarter-scale models of a cyclist and a motorcycle carrying two persons were made by $\mathrm{CNC}$ cutting from ABS (acrylonitrile butadiene styrene) (Fig. 2). The geometry of the model cyclist was obtained by scanning (Artec Eva 3D scanner) a male cyclist with height $183 \mathrm{~cm}$ and mass $72 \mathrm{~kg}$. He was positioned in time-trial position wearing an aerodynamic helmet and a standard tight-fitting racing suit with long sleeves. The resulting frontal area was $0.34 \mathrm{~m}^{2}$. Written consent of the cyclist was obtained. After scanning, the scan facial geometry characteristics were altered/ smoothened to make the athlete unrecognizable. The procedure of processing the body geometry and reporting the
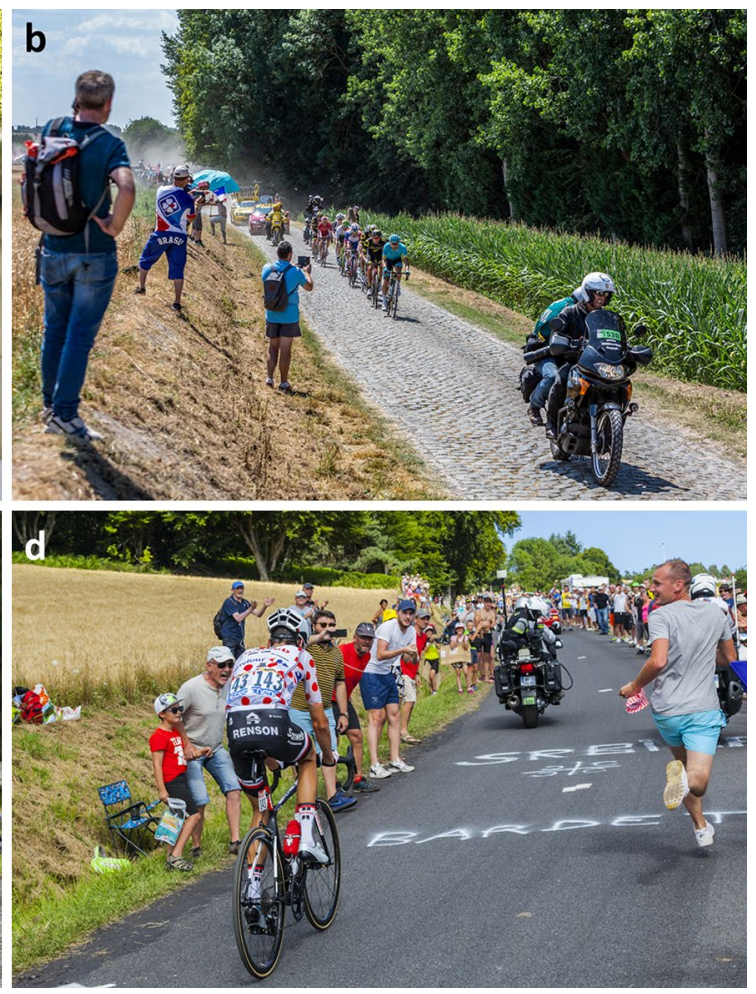

sports/Shutterstock.com; b-d Radu Razvan/Shutterstock.com; all photos reproduced with permission) 

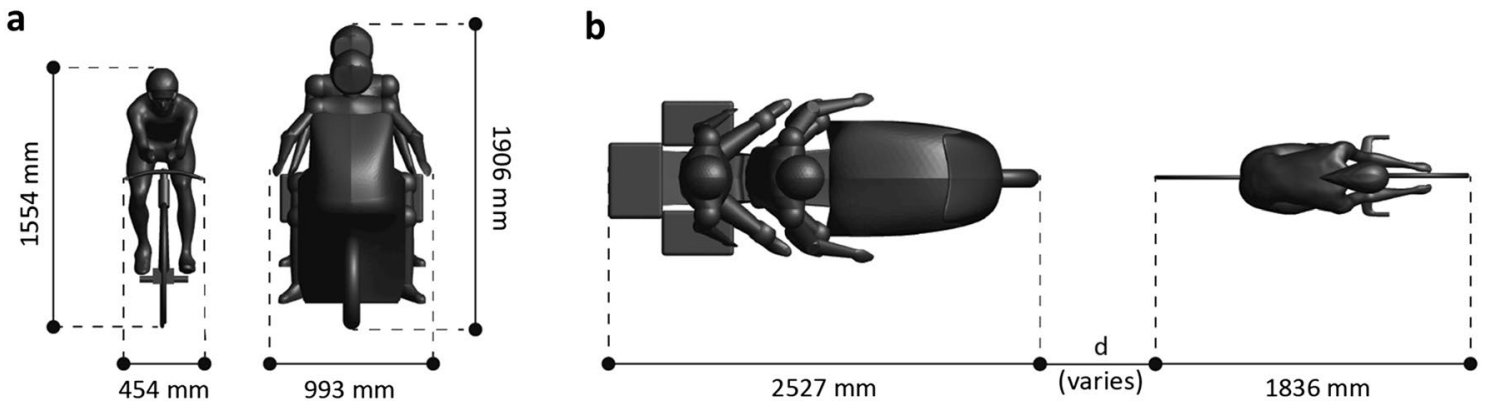

Fig. 2 Geometry and main dimensions in full scale of the cyclist and motorcycle models

results was approved by the ethical board committee of Eindhoven University of Technology with reference code (ERB2020BE_1859456_WT). The bicycle was a standard race bicycle with tri-spoke front wheel and disk rear wheel and a time-trial handlebar. CAD software was used to simplify the bicycle geometry by removing gears, chain, cabling etc. The geometry of the motorcycle was created manually based on photographs of components of actual motorcycle geometries (Fig. 2). The frontal area of the motorcycle was $1.21 \mathrm{~m}^{2}$.

The wind tunnel (WT) tests were performed in the WT of Eindhoven University of Technology [31]. A dedicated setup with an elevated sharp-edged smooth horizontal plate and embedded force balance was developed to limit boundary layer development (Fig. 3). The blockage ratio of the set-up was about $2 \%$, which is below the recommended maximum of 5\% [32]. Due to the elevated sharp-edged plate, the resulting boundary layer height at the position of the cyclist was limited to $0.06 \mathrm{~m}$ and the measured longitudinal turbulence intensity above this $0.06 \mathrm{~m}$ was $0.3 \%$. The height of $0.06 \mathrm{~m}$ corresponded to the height of the feet of the cyclist, so only a very small fraction of the frontal area of the cyclist was below this height. The drag force on the cyclist was measured with a force transducer designed specifically for highaccuracy quarter-scale cyclist WT tests [25] with an equipment accuracy of $0.001 \mathrm{~N}$. Data were sampled at $10 \mathrm{~Hz}$ for $60 \mathrm{~s}$. Tests were performed at wind speeds of 15, 20, 25 and $30 \mathrm{~m} / \mathrm{s}$ to detect Reynolds number independence, which was noted above $20 \mathrm{~m} / \mathrm{s}$. The Reynolds-number independent results were retained and are reported in the results section.

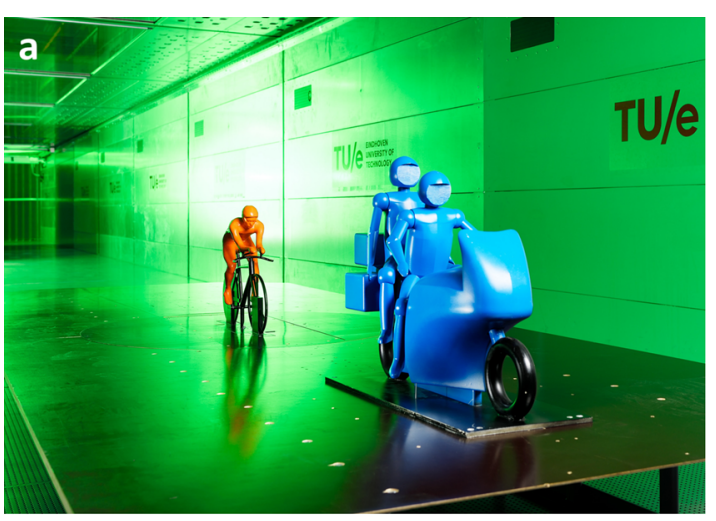

C

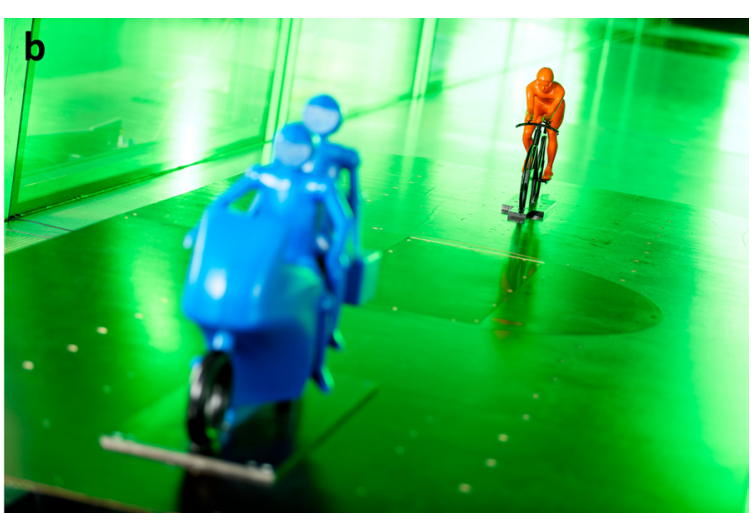

d
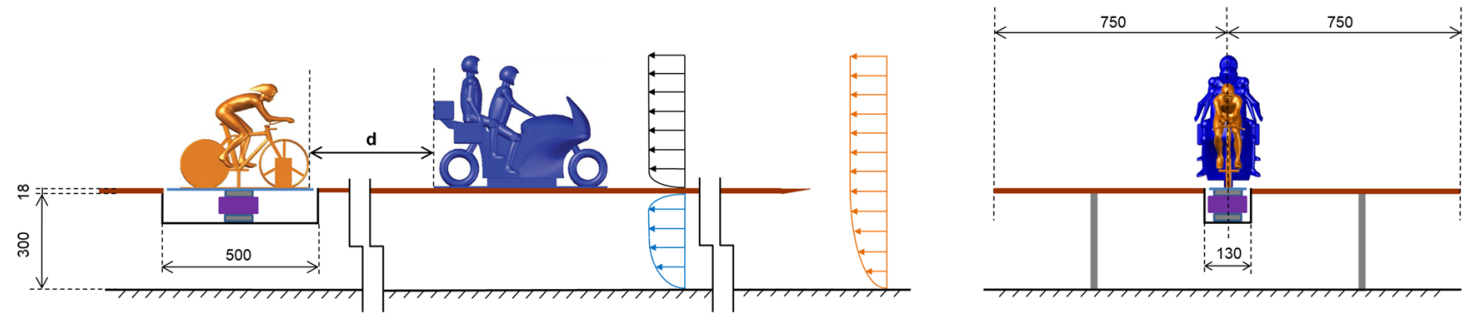

Fig. 3 a, b Photos of wind tunnel set-up; $\mathbf{c}, \mathbf{d}$ line drawing of wind tunnel set-up: cyclist behind motorcycle on elevated sharp-edged plate; $\mathbf{c}$ side view; $\mathbf{d}$ front view. Dimensions in $\mathrm{mm}$ 
It was assumed that there was no crosswind, no head wind and no tail wind, therefore the WT speed represented the riding velocity. A range of wheel-to-wheel separation distances was tested, the full-scale values (i.e. 4 times larger than the WT values) of which are: $d=0.12,0.24,0.48,1.32,2.64$, $4.8,10,15,20,30,40$ and $50 \mathrm{~m}$. To assess the repeatability of the experimentally obtained drag values, the isolated cyclist was tested five times throughout the measurement campaign. Based on these measurements, the repeatability of the obtained drag values was found to be $0.7-0.9 \%$, which corresponded to drag differences of about $0.3 \mathrm{~N}$ for the isolated cyclist. Drag measurements were corrected to match the conditions set in the computational fluid dynamics (CFD) simulations of 101,325 Pa (standard atmosphere), $15{ }^{\circ} \mathrm{C}, 15 \mathrm{~m} / \mathrm{s}$ (a top time trial speed) and full geometrical scale. The measurement results will be reported together with the CFD results in the next sections.

\section{CFD simulations: computational settings and parameters}

The CFD simulations were performed at full scale. The computational geometries of the cyclist and motorcycle were identical to those of the WT models except for the WT model bottom plate, the vertical reinforcement bars in the cycling wheels and the geometrical scale (1:1 versus $1: 4)$. The computational domain was a rectangular prism with width $30.3 \mathrm{~m}$ and height $24 \mathrm{~m}$. The length varied with the separation distance $\mathrm{d}$. The distance between the domain inlet face and the motorcycle front wheel was $18 \mathrm{~m}$. The distance between the bicycle rear end and the domain outlet face was $45 \mathrm{~m}$. The lateral distance between motorcycle/ cyclist and domain side face was about $14 \mathrm{~m}$. The blockage ratio was $0.1 \%$. These domain sizes were larger than those stipulated in CFD best practice guideline documents [33-36] and the resulting blockage ratio was below the recommended maximum of 5\% [33-36]. In the simulations, the wheels of the cyclist and motorcycle were not touching the ground, i.e. the bottom of the computational domain. This is one of the two typical CFD modeling approaches ("gap approach" versus "step approach") for wheel-ground contact modeling [37]. The gap approach was used to facilitate grid generation and ensure grid quality in what would be the contact area between wheel and ground. It has been shown that this modeling approach has negligible impact on the resulting drag values [37].

The hybrid hexahedral-tetrahedral computational grids were generated based on grid convergence analysis (not reported here) and on CFD grid generation guidelines [34, $35,38,39]$. This analysis indicated the necessity of a walladjacent cell size of $20 \mu \mathrm{m}(=0.02 \mathrm{~mm})$ and 40 layers of prismatic cells near the surfaces of the cyclist and motorcycle (Fig. 4). This was required to accurately resolve the thin boundary layer including the laminar sublayer. The dimensionless wall unit $y^{*}$ had values that are generally below 1 and everywhere below 5 . Here, $y^{*}$ was defined as $y^{*}=u^{*} y_{\mathrm{P}} / \nu$ where $y_{\mathrm{P}}$ is the distance from the wall-adjacent

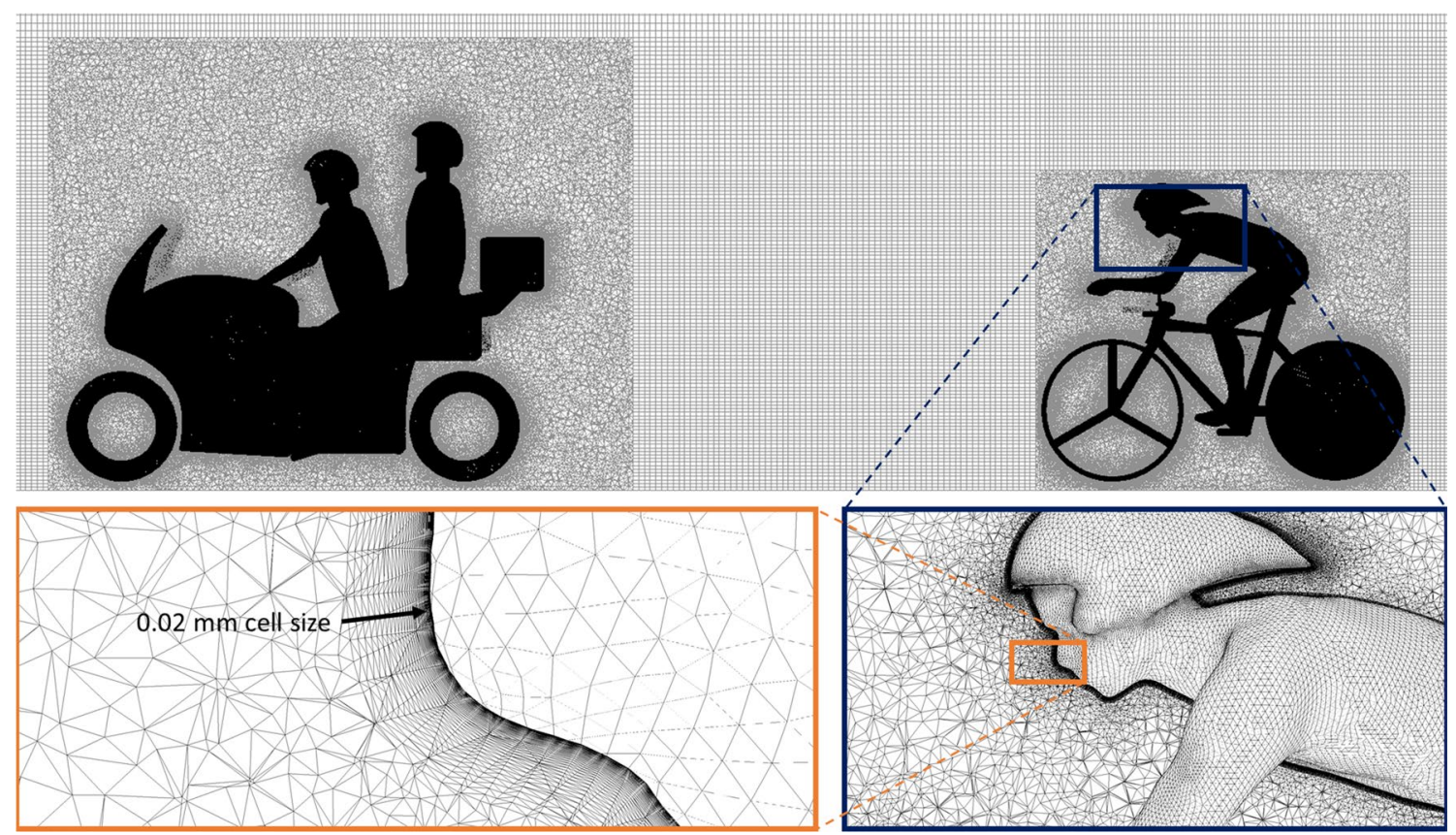

Fig. 4 Computational grid on motorcycle and cyclist surfaces and in vertical centerplane for separation distance $d=2.64 \mathrm{~m}$. Minimum cell size: $0.02 \mathrm{~mm}$. Total cell count: 53.1 million 
cell center point $\mathrm{P}$ to the wall and $u^{*}=C_{\mu}{ }^{1 / 4} k_{\mathrm{P}}{ }^{1 / 2}$. $C_{\mu}$ is a constant $(=0.09)$ and $k_{\mathrm{P}}$ is the turbulent kinetic energy in point $\mathrm{P}$. Note that generally the parameters $y^{+}$and $u^{+}$are used instead of $y^{*}$ and $u^{*}$ but that the latter parameters have the advantage that they can also be used to specify grid resolution requirements at flow field positions where the shear stress is zero, such as stagnation and reattachment points. At these positions, $y^{+}$is zero, irrespective of the local grid resolution $y_{\mathrm{P}}$, and therefore the parameter $y^{+}$cannot be used to specify the grid requirements. The parameter $y^{*}$ however will not be zero because it is based on $k_{\mathrm{P}}$. The grid convergence analysis also indicated the necessity of a cell size of $0.03 \mathrm{~m}$ in the area between motorcycle and cyclist. Figure 4 shows the grid resolution on the surface of the cyclist, motorcycle and in the vertical centerplane. The total cell count varied with the separation distance $d$. The grid for the isolated cyclist contained $27.5 \times 10^{6}$ cells and the grids for $d=2.64,10$ and $50 \mathrm{~m}$ had $53.1 \times 10^{6}, 54.6 \times 10^{6}$ and $76.9 \times 10^{6}$ cells, respectively. The high aspect ratio cells as used in the boundary layer region were suitable for the simulations in this paper. They were indeed suitable for Reynolds-averaged Navier-Stokes (RANS) simulations but also for the Scale Adaptive Simulations (SAS), because the latter apply RANS in the near-wall regions.

At the inlet, a uniform velocity of $15 \mathrm{~m} / \mathrm{s}$ was imposed, which represents the riding velocity. As in the WT tests, it was assumed that there was no crosswind, no head wind and no tail wind. At the outlet, zero static gauge pressure was set. The surfaces of the motorcycle and cyclist were no-slip walls, where the cyclist body (not the bicycle) and the motorcycle had a surface roughness with equivalent sand-grain roughness height $k_{\mathrm{S}}=0.1 \mathrm{~mm}$. The bottom, side and top surfaces of the domain were slip walls. The inlet turbulence intensity had to be set to $0.5 \%$ to obtain the same approach-flow value of $0.3 \%$ in the region directly upstream of the motorcycle as in the wind tunnel. This was required because the turbulence intensity decayed from 0.5 to $0.3 \%$ from the inlet of the computational domain to the position of the motorcycle model.

Two sets of CFD simulations were performed. First, for all distances $d$, 3D RANS simulations were conducted with the Shear Stress Transport (SST) k- $\omega$ model [40] with curvature correction. Pressure-velocity coupling was taken care of by the coupled algorithm with pseudo-transient underrelaxation and a pseudo-transient time step of $0.01 \mathrm{~s}$. Pressure interpolation was second order, gradient interpolation was performed with the Green-Gauss node based scheme and second-order discretization schemes were used for both the convection terms and the viscous terms of the governing equations. The simulations were performed with the commercial CFD code Ansys Fluent 16.1 and 19.1 [41, 42]. Simulations were run for a total of 5000 pseudo-transient time steps and averaging of the results was performed for the last 4000 time steps. Tests confirmed that the total number of 5000 was sufficient to obtain a constant moving average of the sampled drag force.

Second, for separation distances greater than $4.8 \mathrm{~m}$, SAS simulations were performed based on the SST k- $\omega$ model. SAS is an improved URANS formulation that allows turbulence spectra to be resolved in the detached regions of the flow [43]. This results in a Large Eddy Simulation (LES)like behavior in the unsteady regions of the flow field. The SAS-SST $k-\omega$ model works in RANS mode with the SST $\mathrm{k}-\omega$ model for the wall-bounded flow and switches to scaleresolving mode in the large and unstable separation zones of the flow. Pressure-velocity coupling was taken care of by the PISO algorithm. Pressure interpolation was second order, gradient interpolation was performed with the Green-Gauss node based scheme. Bounded central differencing was used for the momentum equations and second-order discretization for the turbulence model equations. Time discretization was bounded second order implicit. Also the SAS simulations were performed with the commercial CFD code Ansys Fluent 16.1 [41]. For these simulations, a time step sensitivity analysis was performed to determine a suitable time step $\Delta t$. Keeping the CFL number equal or below 1 in the region between motorcycle and cyclist yielded $\Delta t=\Delta x / U=0.03 / 15=0.002 \mathrm{~s}$. For the configuration with the isolated cyclist and that with cyclist behind the motorcycle at $d=10 \mathrm{~m}, \Delta t=0.002,0.001$ and $0.0005 \mathrm{~s}$ were tested. For the isolated cyclist, $\Delta \mathrm{t}=0.001 \mathrm{~s}$ and $0.0005 \mathrm{~s}$ only yielded a cyclist drag force that was 0.1 and $0.3 \%$ different, respectively, from that for $0.002 \mathrm{~s}$. For $d=10 \mathrm{~m}$, these deviations were 0.1 and $0.4 \%$, respectively. Therefore, $\Delta t=0.002 \mathrm{~s}$ was retained for all SAS-SST $\mathrm{k}-\omega$ simulations. The number of time steps required to obtain a constant moving average of the sampled drag values ranged from 8000 to 50,000. Note that e.g. for $d=2.64 \mathrm{~m}$, the time to run one SAS-SST k- $\omega$ time step was about 10 times longer than for one RANS pseudo-transient time step. Therefore, RANS was the more economical approach but it is less accurate than SAS [44].

\section{CFD simulations: results and validation}

\subsection{Velocity and pressure fields}

Figure 5 presents the RANS results for $d=0.24 \mathrm{~m}$ in terms of contours of the mean velocity ratio $K$ and the mean pressure coefficient $C_{\mathrm{P}}$ in a horizontal plane at $1 \mathrm{~m}$ height and in the vertical centerplane. The velocity ratio $K$ was defined as the magnitude of the local 3D velocity vector divided by the inlet speed (=motorcycle and cyclist riding speed) of $U=15 \mathrm{~m} / \mathrm{s}$. The pressure coefficient was defined as $C_{\mathrm{P}}=\left(P-P_{0}\right) /\left(0.5 \rho U^{2}\right)$ with $\mathrm{P}$ the local static pressure and $P_{0}$ the reference static pressure. Figure $5 \mathrm{a}$, b display 

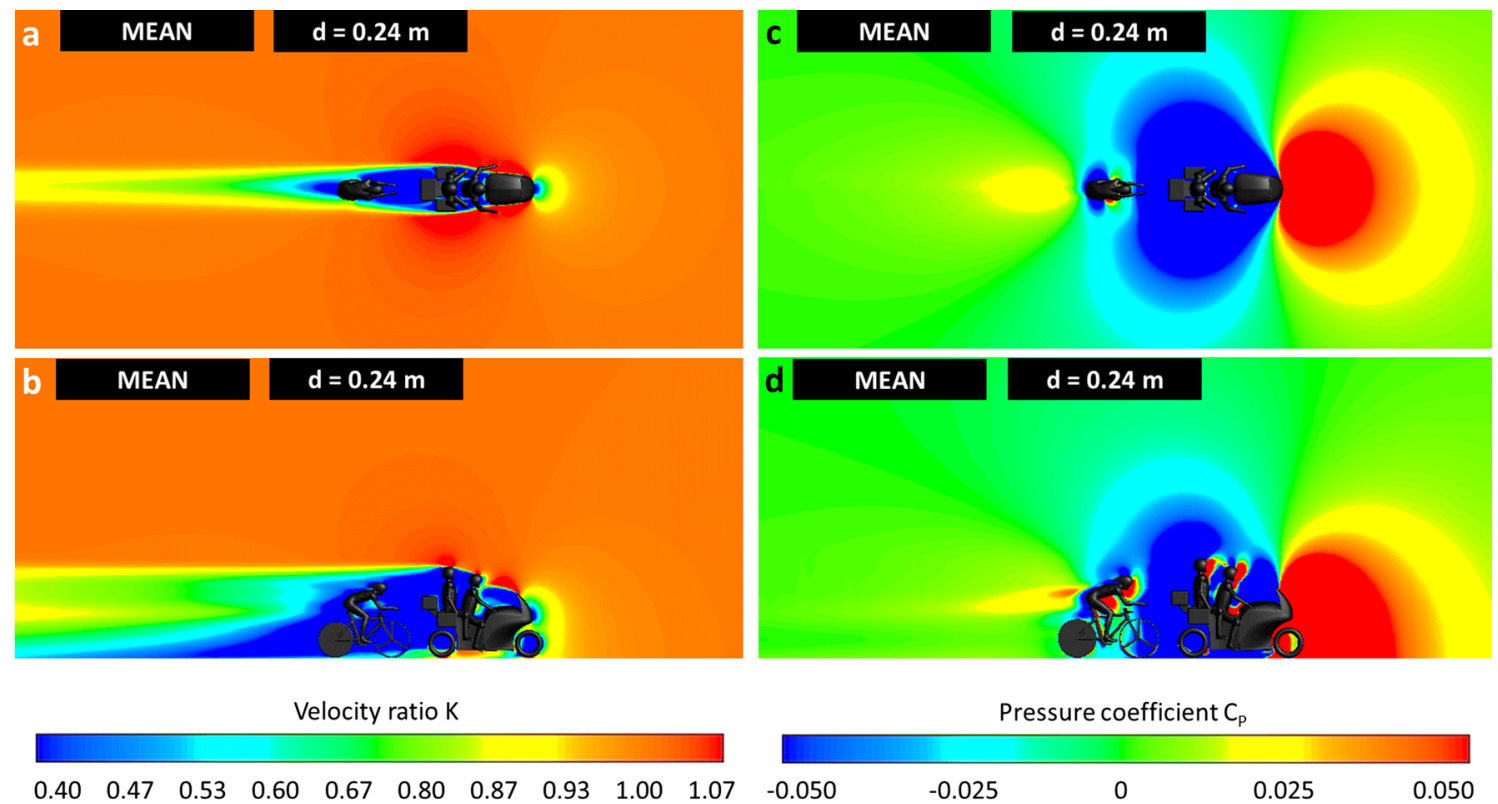

Fig. 5 Results of RANS simulations: a, b contours of mean velocity ratio $K$ in horizontal plane at $1 \mathrm{~m}$ height and in vertical centerplane for separation distance $d=0.24 \mathrm{~m}$. c, $\mathbf{d}$ Same for mean pressure coefficient $C_{\mathrm{P}}$

the time-averaged or mean contours by averaging over the last 4000 time steps. The cyclist was clearly embedded in the near wake or slipstream behind the motorcycle where the momentum deficit is pronounced. Figure $5 \mathrm{c}$, d show the mean $C_{\mathrm{P}}$ contours indicating that the cyclist was substantially encompassed in the low pressure area behind the motorcycle. The resulting cyclist drag reduction was $75 \%$.
Figure 6 presents the RANS results for $d=2.64 \mathrm{~m}$. For this distance, the cyclist was situated further downstream in the wake behind the motorcycle where the momentum deficit was less pronounced as in Fig. 5. This was clearly shown in Fig. 6a, b where the cyclist was immersed in the part of the wake were momentum recovery was substantial, and in Fig. 6c, d, where the area in front of the cyclist was
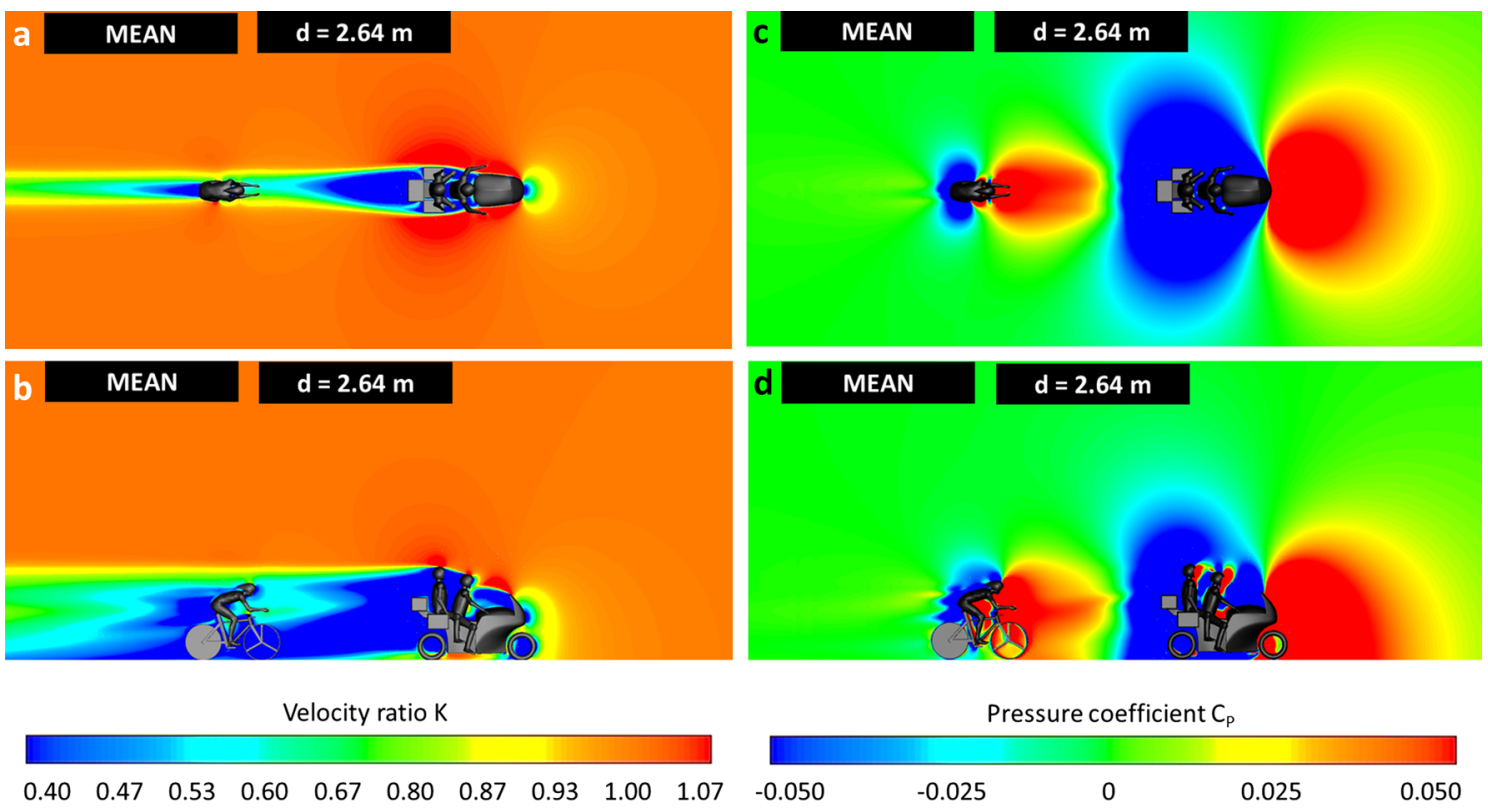

Fig. 6 Results of RANS simulations: a, b contours of mean velocity ratio $K$ in horizontal plane at $1 \mathrm{~m}$ height and in vertical centerplane for separation distance $d=2.64 \mathrm{~m}$. c, $\mathbf{d}$ Same for mean pressure coefficient $C_{\mathrm{P}}$ 
characterized by substantial overpressure associated with the impinging flow on the cyclist. The resulting cyclist drag reduction was $48 \%$.

Figures 7 and 8 present the SAS-SST $\mathrm{k}-\omega$ results for $d=10 \mathrm{~m}$. The cyclist was situated in the far wake. The instantaneous images in Figs. 6a, c and 7a, c show that the slipstream with pronounced vortex shedding was resolved with an LES-like behavior of the computed flow. Figure 7b, $\mathrm{d}$ show that the momentum recovery in the area between the motorcycle and the cyclist was substantial, compared to $d=2.64 \mathrm{~m}$. Figure $8 \mathrm{~b}, \mathrm{~d}$ display a pressure distribution around the cyclist that resembles that of an isolated cyclist [27], due to the large distance between motorcycle and cyclist. The resulting cyclist drag reduction was $23 \%$. Animations of the SAS-SST $\mathrm{k}-\omega$ simulations for $d=10 \mathrm{~m}$ and $d=20 \mathrm{~m}$ are provided in (Supplementary Material 1-5).

\subsection{Drag reduction percentages}

Figure 9a shows the drag reductions as a function of $d$. For every distance, the values by the WT tests and the RANS simulations are shown. For $d$ up to $4.8 \mathrm{~m}$, the agreement between the RANS and the WT results was good to fair, with deviations between 0.7 and $1.7 \%$ for $d=0.12 \mathrm{~m}$ and $4.8 \mathrm{~m}$, respectively. Larger deviations however occurred for
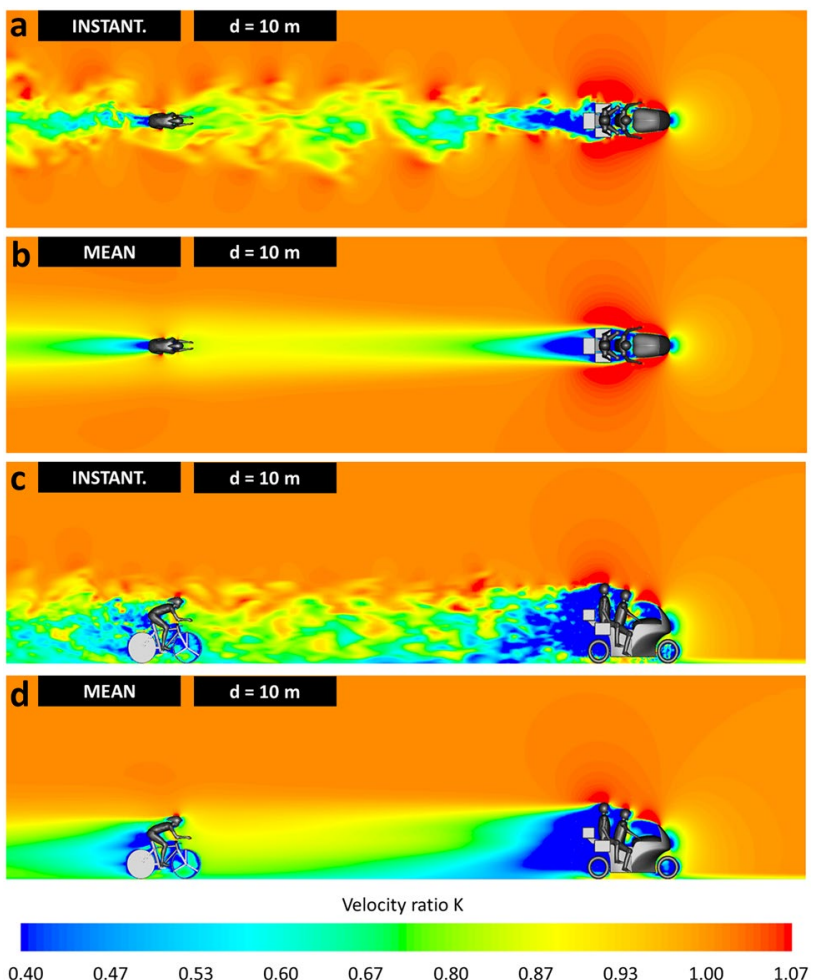

Fig. 7 Results of SAS simulations: contours of velocity ratio $K$ in horizontal plane at $1 \mathrm{~m}$ height and in vertical centerplane for separation distance $d=10 \mathrm{~m}$. a, c Instantaneous; $\mathbf{b}, \mathbf{d}$ mean
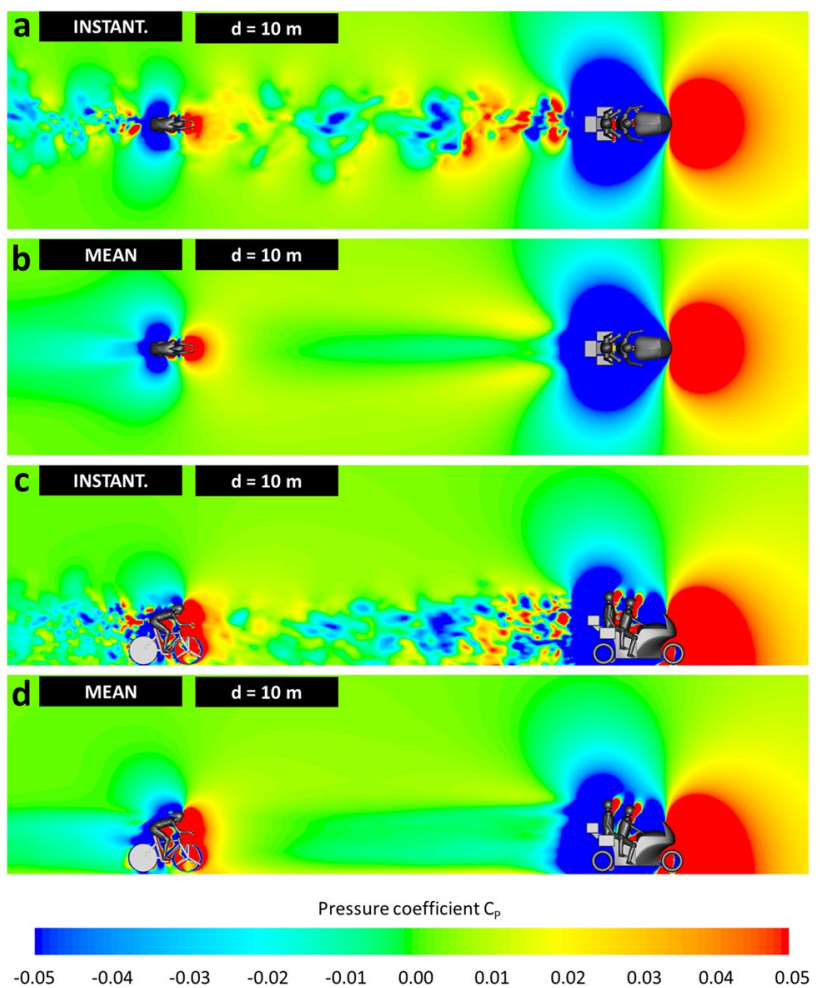

Fig. 8 Results of SAS simulations: contours of pressure coefficient $C_{\mathrm{P}}$ in horizontal plane at $1 \mathrm{~m}$ height and in vertical centerplane for separation distance $d=10 \mathrm{~m}$. a, c Instantaneous; $\mathbf{b}, \mathbf{d}$ mean

$d=10 \mathrm{~m}$ and beyond. These deviations are attributed to the well-known deficiencies of RANS simulations based on the Boussinesq eddy-viscosity hypothesis that overpredict the length of the wake and underestimate the velocity magnitude in this wake. These deficiencies have been reported in wind engineering studies (e.g. [45, 46]), and start acting particularly in the far wake, rendering the results from the RANS simulations for $d=10 \mathrm{~m}$ and beyond insufficiently accurate. For that reason, scale-resolving simulations (SAS) needed to be engaged, which provided a better agreement with the WT tests, with deviations between 8.0 and $1.5 \%$ for $d=10 \mathrm{~m}$ and $50 \mathrm{~m}$, respectively.

\section{Potential time gains}

To convert the drag reduction percentages to potential speed increases and potential time gains, the power model by Martin et al. [47] was employed. In this model, the required power is expressed as:

$P_{\mathrm{tot}}=\left(P_{\mathrm{ad}}+P_{\mathrm{rr}}+P_{\mathrm{wb}}+P_{\mathrm{pe}}+P_{\mathrm{ke}}\right)\left(\frac{1}{\eta}\right)$. 
Fig. 9 a Drag reduction percentage as a function of the separation distance $d$, as obtained by wind tunnel tests, RANS CFD and SAS CFD. b Time gains per kilometer and per minute at a non-drafting speed of $54 \mathrm{~km} / \mathrm{h}$ and as a function of the separation distance $d$
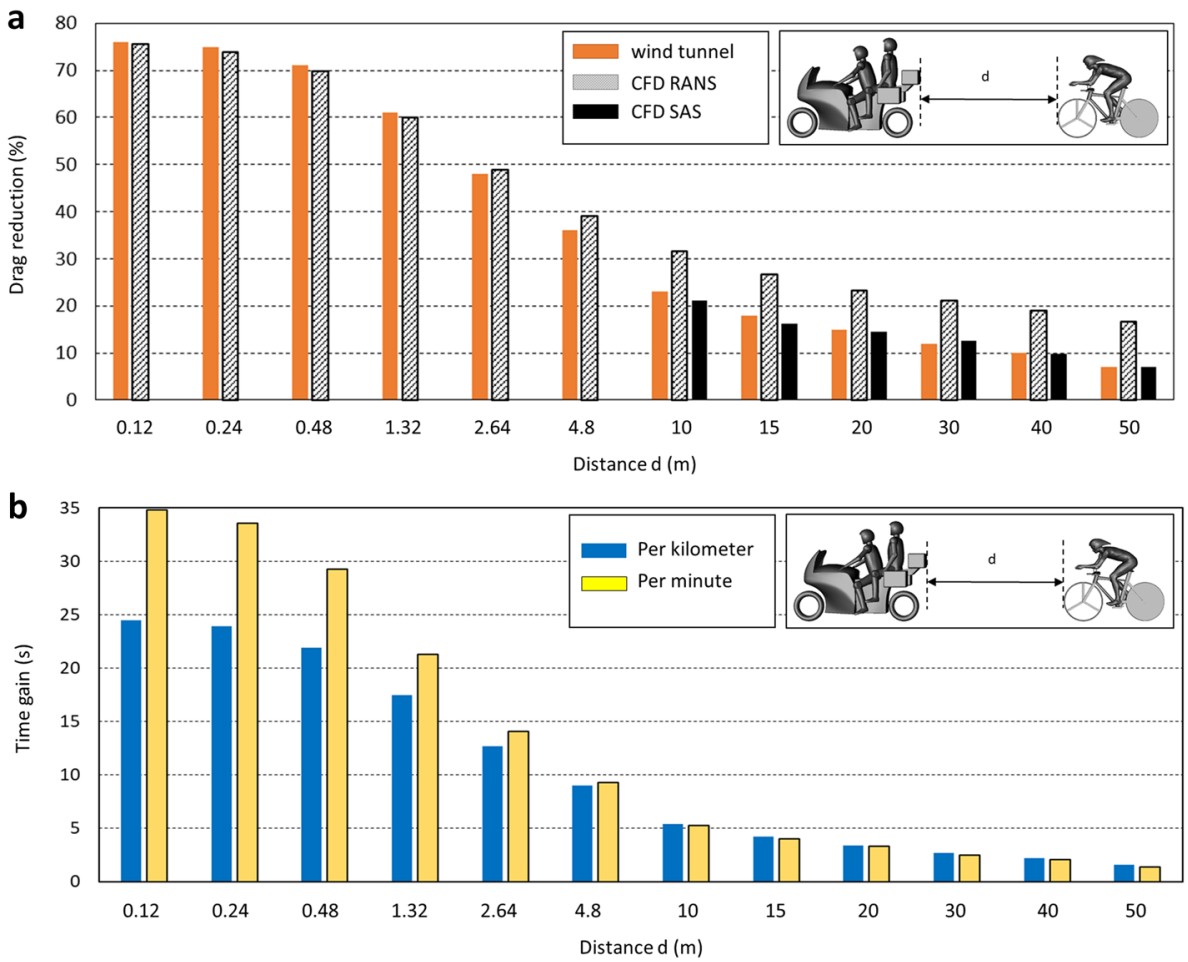

With $P_{\text {ad }}$ the power loss due to aerodynamic drag, $P_{\text {rr }}$ the power loss due to rolling resistance, $P_{\mathrm{wb}}$ the power loss due to friction in the wheel bearings, $P_{\mathrm{pe}}$ the power changes due to a change in potential energy (terrain slopes) and $P_{\mathrm{ke}}$ the power changes due to changes in kinetic energy, i.e. the power to accelerate or that becomes available when the system decelerates. The efficiency $\eta$ is that of the cyclist power transmission, associated to the friction in the drivetrain. For simplicity, we assumed level terrain and constant cycling speed so $P_{\mathrm{pe}}=P_{\mathrm{ke}}=0$, and no crosswind, headwind or tailwind. Then, Eq. (1) can be written more explicitly as [47]:

$P_{\text {tot }}=\left[0.5 \rho U^{3}\left(C_{\mathrm{D}} A+F_{\mathrm{w}}\right)+U C_{\mathrm{rr}} m g+U(91+8.7 U) \times 10^{-3}\right] \frac{1}{\eta}$.

The following values were considered for each of the parameters. The density $\rho=1.225 \mathrm{~kg} / \mathrm{m}^{3}$, the reference riding velocity of the isolated cyclist $U=15 \mathrm{~m} / \mathrm{s}$, the drag area $C_{\mathrm{D}} A=0.21 \mathrm{~m}^{2}$, the rotational drag area for three-spoke/ disk wheels $F_{\mathrm{w}}=0.001 \mathrm{~m}^{2}$, the rolling resistance coefficient $C_{\mathrm{rr}}=0.002$, the mass of the cyclist-bicycle system $m=75 \mathrm{~kg}$, the gravitational constant $g=9.81 \mathrm{~m} / \mathrm{s}^{2}$ and the chain efficiency $\eta=0.97698$. With these values and the above-mentioned assumptions, for the isolated cyclist at $15 \mathrm{~m} / \mathrm{s}, P_{\text {tot }}=472.5 \mathrm{~W}$. This is a high value but not unrealistic for professional cyclists, even for long durations. Note that Bradley Wiggins is expected to have delivered $440 \mathrm{~W}$ during his successful world hour record attempt in London in 2015 [48]. While this power for an hour is exceptional, larger power values for shorter durations-as in moments of drafting behind a motorcycle-are common in professional cycling [49]. To calculate the speed increase and the potential time gains by drafting, it was assumed that the cyclist provides the same power $P_{\text {tot }}(=472.5 \mathrm{~W})$ when drafting as when riding alone. In this case and using the WT drag reduction percentages as input, Table 1 presents the associated speed increase and the potential time gain per $\mathrm{km}$ and per minute, and Fig. $9 \mathrm{~b}$ presents the time gains graphically.

Table 1 Drag reduction and potential speed increases and time gains for the cyclist drafting behind a motorcycle as a function of separation distance $\mathrm{d}$

\begin{tabular}{lllll}
\hline Distance $d(\mathrm{~m})$ & $\begin{array}{l}\text { Drag } \\
\text { reduction } \\
(\%)\end{array}$ & $\begin{array}{l}\text { Speed } \\
\text { increase } \\
(\%)\end{array}$ & $\begin{array}{l}\text { Time gain } \\
\text { per km }(\mathrm{s})\end{array}$ & $\begin{array}{l}\text { Time gain } \\
\text { per min } \\
(\mathrm{s})\end{array}$ \\
\hline 0.12 & 76 & 58.1 & 24.5 & 34.8 \\
0.24 & 75 & 56.1 & 23.9 & 33.6 \\
0.48 & 71 & 48.9 & 21.9 & 29.3 \\
1.32 & 61 & 35.5 & 17.5 & 21.3 \\
2.64 & 48 & 23.5 & 12.7 & 14.1 \\
4.8 & 36 & 15.5 & 9.0 & 9.3 \\
10 & 23 & 8.9 & 5.4 & 5.3 \\
15 & 18 & 6.7 & 4.2 & 4.0 \\
20 & 15 & 5.4 & 3.4 & 3.3 \\
30 & 12 & 4.3 & 2.7 & 2.5 \\
40 & 10 & 3.5 & 2.2 & 2.1 \\
50 & 7 & 2.4 & 1.6 & 1.4 \\
\hline
\end{tabular}




\section{Discussion}

Table 1 indicates that the potential time gains for a cyclist drafting behind a motorcycle are large, even when drafting at large distances such as between 30 and $50 \mathrm{~m}$. Time trials are sometimes won by fractions of a second. For example, in the 2016 Giro d'Italia individual time trial in Apeldoorn, the Netherlands, Tom Dumoulin gained the victory with only $0.02 \mathrm{~s}$ ahead of Primoz Roglic. Considering these tiny time differences between first and second place, it is clear that drafting behind a motorcycle can influence the outcome of races. Therefore, the concern in the cycling community that drafting behind motorcycles can provide benefits that can influence the outcome of cycling races (e.g. [29, 30]) is justified. The distances $d$ in Table 1 could be divided in four categories: (1) very small $(d=0.12-1.32 \mathrm{~m})$, small $(d=2.64-4.8 \mathrm{~m})$, moderate $(d=10-30 \mathrm{~m})$ and large distances $(d=40-50 \mathrm{~m})$. The very small distances do not tend to occur in races and are merely provided to give a more complete view of possible drafting effects. Note however that they do occur in record speed attempts or in some track races. The small distances can occur but generally only for a short period of time. The moderate distances do occur quite often (Fig. 1), and the associated time gains are large. Note that the precise values of drag reduction and time gains provided in this paper are specific to the cyclist and motorcycle geometry tested and the meteorological conditions mentioned above. Finally, while very large separation distances also occur often, the presence of crosswind can render it impossible for the cyclist to benefit from the motorcycle slipstream.

Crosswind, head wind or tail wind will change the drag reductions and time gains reported above. When crosswind is present, the slipstream behind the motorcycle will be at an offset from the straight line behind the motorcycle, making it more difficult for the cyclist to be positioned in this slipstream. This is similar to cyclists trying to remain in each other's slipstream in crosswind conditions, which is attempted by forming echelons, where the riders are riding in staggered rather than in-line arrangement. Therefore, as the separation distance becomes larger, it might become increasingly difficult or even impossible for the cyclist to remain positioned in the slipstream of the motorcycle. For head wind, the difference in aerodynamic drag behind a rider drafting behind a motorcycle and an unsheltered rider will become larger. Therefore, also the time gains in Table 1 will increase. Conversely, for tailwind, the opposite holds, and the time gains will decrease.

The present rules and guidelines of the UCI do not prevent drafting situations where cyclists can gain large aerodynamic and time benefits over their opponents. The most recent guidelines for "vehicle circulation in the race convoy" [28] only stipulate when and which motorcycles can enter the gaps between breakaway riders and the following riders in terms of time differences. The larger the time differences, the more motorcycles can enter the gap. However, interestingly, in the UCI Cycling Regulations Part 2 for Road Races [50], the motorcycles are sometimes specifically referred to as "motorcycles" but often also as "vehicles". This is shown for example in Article 2.3.023 that lists vehicles including different types of motorcycles. Chapter XII of these regulations deals with race incidents and item 4.7 in the table in article 2.12.007 refers to penalties for sheltering behind or taking advantage of the slipstream of a vehicle. However, no further specifications are provided. This suggest that the issue with drafting behind motorcycles is not a total lack of regulation but rather the lack of specific and clear rules for motorcycles and a lack of effectiveness in imposing such rules. Therefore, it seems imperative that the UCI modifies their rules and guidelines to prevent these undesired and unfair aerodynamic benefits by drafting behind motorcycles. Nevertheless, solutions might not be straightforward. Motorcycles might be asked to ride not directly in a straight line in front of the cyclists, as they do in Fig. 1. However, as motorcycles will position themselves more laterally, the cyclists will have the natural tendency to also change their own lateral position to remain positioned in the motorcycle slipstream. In other cases, e.g. Fig. 1b, d, the roads might be too narrow to allow a staggered position of motorcycle and cyclist. A potential solution could be the use of drones for television recording, to reduce the number of motorcycles in the race convoy to a minimum.

\section{Conclusion}

While it is well-known that drafting behind a motorcycle provides aerodynamic benefits, to the best of our knowledge, the extent of these benefits had not yet been reported in the scientific literature. Therefore, in the present study, wind tunnel measurements and CFD simulations were performed. Drag reductions were measured and computed for a situation without crosswind, head wind or tailwind. A power model was used to convert these drag reductions into potential time gains. Hereby it was assumed that the isolated cyclist speed is $54 \mathrm{~km} / \mathrm{h}$. The study showed that the drag reductions could be accurately assessed by RANS simulations with pseudotransient under-relaxation, however only up to a distance of about $4.8 \mathrm{~m}$. For larger distances, more advanced and computationally expense scale-resolving simulations with the SAS-SST k- $\omega$ model were performed. For drafting distances of $2.64,10,30$ and $50 \mathrm{~m}$, the drag reductions were 48, 23, 12 and 7\%, respectively. The associated time gains were $12.7,5.4,2.7$ and $1.6 \mathrm{~s}$ per $\mathrm{km}$. Because cycling races 
are sometimes won by a few seconds or less, these time gains can influence the outcome of the races. Therefore, the common concern in the cycling community that drafting behind motorcycles can influence the outcome of races is correct. The current rules and guidelines of the International Cycling Union (UCI) do not prevent situations where drafting can occur. The rules and guidelines need to be adjusted to prevent these undesired aerodynamic benefits.

Acknowledgements We thank the technical support team of the Wind Tunnel Laboratory at the Department of the Built Environment at Eindhoven University of Technology: Ing. Jan Diepens, Geert-Jan Maas and Stan van Asten. We gratefully acknowledge the feedback on this research provided by Dr. Fred Grappe, Performance Director of Equipe Cycliste Groupama-FDJ and Scientific Expert in Sports at the Université des Sports de Besançon in France. The authors are very grateful to those who provided computational resources for this work. Part of this work was performed by simulations on the Ansys Cloud. This work was also sponsored by NWO Exacte en Natuurwetenschappen (Physical Sciences) for the use of supercomputer facilities, with financial support from the Nederlandse Organisatie voor Wetenschappelijk Onderzoek (Netherlands Organization for Scientific Research, NWO). We acknowledge the partnership with Ansys CFD.

\section{Compliance with ethical standards}

Conflict of interest This work was unfunded work and performed as a self-defined inter-university project by the researchers involved. The first author had no involvement in the anonymous peer-review process. The review process resulted in additional valuable discussion items that have improved the article.

Open Access This article is licensed under a Creative Commons Attribution 4.0 International License, which permits use, sharing, adaptation, distribution and reproduction in any medium or format, as long as you give appropriate credit to the original author(s) and the source, provide a link to the Creative Commons licence, and indicate if changes were made. The images or other third party material in this article are included in the article's Creative Commons licence, unless indicated otherwise in a credit line to the material. If material is not included in the article's Creative Commons licence and your intended use is not permitted by statutory regulation or exceeds the permitted use, you will need to obtain permission directly from the copyright holder. To view a copy of this licence, visit http://creativecommons.org/licenses/by/4.0/.

\section{References}

1. Kyle CR, Burke ER (1984) Improving the racing bicycle. Mech Eng 106(9):34-45

2. Grappe F, Candau R, Belli A, Rouillon JD (1997) Aerodynamic drag in field cycling. Ergonomics 40:1299-1311

3. Lukes RA, Chin SB, Haake SJ (2005) The understanding and development of cycling aerodynamics. Sport Eng 8:59-74

4. Crouch TN, Burton D, LaBry ZA, Blair KB (2017) Riding against the wind: a review of competition cycling aerodynamics. Sport Eng 20:81-110

5. Malizia F, Blocken B (2020) Bicycle aerodynamics: history, state of the art and future perspectives. J Wind Eng Ind Aerodyn 200:104134

6. Defraeye T, Blocken B, Koninckx E, Hespel P, Carmeliet J (2010) Aerodynamic study of different cyclist positions:
CFD analysis and full-scale wind-tunnel tests. J Biomech 43:1262-1268

7. Fintelman DM, Sterling M, Hemida H, Li FX (2014) Optimal cycling time trial position models: aerodynamics versus power output and metabolic energy. J Biomech 47:1894-1898

8. Barry N, Burton D, Sheridan J, Thompson M, Brown NAT (2015) Aerodynamic performance and riding posture in road cycling and triathlon. Proc Inst Mech Eng Part P J Sport Eng Technol 229:28-38

9. Blocken B, van Druenen T, Toparlar Y, Andrianne T (2018) Aerodynamic analysis of different cyclist hill descent positions. J Wind Eng Ind Aerodyn 181:27-45

10. Blocken B, van Druenen T, Toparlar Y, Andrianne T (2019) CFD analysis of an exceptional cyclist sprint position. Sport Eng 22:1-11

11. Merkes PFJ, Menaspà $P$, Abbiss C (2019) Reducing aerodynamic drag by adopting a novel road cycling sprint position. Int J Sports Physiol Perform 14:733-738

12. Crouch TN, Burton D, Brown NAT, Thompson MC, Sheridan J (2014) Flow topology in the wake of a cyclist and its effect on aerodynamic drag. J Fluid Mech 748:5-35

13. Crouch TN, Burton D, Thompson MC, Brown NAT, Sheridan J (2016) Dynamic leg-motion and its effect on the aerodynamic performance of cyclists. J Fluids Struct 65:121-137

14. Griffith MD, Crouch TN, Thompson MC, Burton D, Sheridan J, Brown NAT (2014) Computational fluid dynamics study of the effect of leg position on cyclist aerodynamic drag. J Fluids Eng Trans ASME 136:1-9

15. Zdravkovich, (1992) Aerodynamics of bicycle wheel and frame J Wind Eng Ind Aerodyn 40(1):55-70

16. Chowdhury H, Alam F, Khan I (2011) An experimental study of bicycle aerodynamics. Int J Mech Mat Eng 6:269-274

17. Malizia F, Montazeri H, Blocken B (2019) CFD simulations of spoked wheel aerodynamics in cycling: impact of computational parameters. J Wind Eng Ind Aerodyn 194:103988

18. Beaumont F, Taiar R, Polidori G, Trenchard H, Grappe F (2018) Aerodynamic study of time-trial helmets in cycling racing using CFD analysis. J Biomech 67:1-8

19. Novak J, Burton D, Crouch TN (2019) Aerodynamic test results of bicycle helmets in different configurations: towards a responsive design. Proc Inst Mech Eng Part P J Sport Eng Technol 233:268-276

20. Blocken B, Defraeye T, Koninckx E, Carmeliet J, Hespel P (2013) CFD simulations of the aerodynamic drag of two drafting cyclists. Comput Fluids 71:435-445

21. Defraeye T, Blocken B, Koninckx E, Hespel P, Verboven P, Nicolai B, Carmeliet J (2014) Cyclist drag in team pursuit: influence of cyclist sequence, stature, and arm spacing. J Biomech Eng 136:1-9

22. Barry N, Burton D, Sheridan J, Thompson M, Brown NAT (2015) Aerodynamic drag interactions between cyclists in a team pursuit. Sport Eng 18:93-103

23. Barry N, Burton D, Sheridan J, Thompson M, Brown NAT (2016) Flow field interactions between two tandem cyclists. Exp Fluids 57:1-14

24. Blocken B, Toparlar Y, van Druenen T, Andrianne T (2018) Aerodynamic drag in cycling team time trials. J Wind Eng Ind Aerodyn 182:128-145

25. Blocken B, van DruenenT TY, Malizia F, Mannion P, Andrianne T, Marchal T, Maas GJ, Diepens J (2018) Aerodynamic drag in cycling pelotons: new insights by CFD simulation and wind tunnel testing. J Wind Eng Ind Aerodyn 179:319-337

26. Blocken B, Toparlar Y (2015) A following car influences cyclist drag: CFD simulations and wind tunnel measurements. J Wind Eng Ind Aerodyn 145:178-186 
27. Blocken B, Toparlar Y, Andrianne T (2016) Aerodynamic benefit for a cyclist by a following motorcycle. J Wind Eng Ind Aerodyn 155:1-10

28. International Cycling Union (2017) Guidelines for vehicle circulation in the race convoy. Version February 2017. https://www. uci.org/inside-uci/publications

29. Robertshaw H (2017) "This has to stop!"-riders slam drafting behind motorbikes in races. https://www.cyclingweekly.com/ news/racing/this-has-to-stop-riders-slam-drafting-behind-motor bikes-in-races-312031. Retrieved on 18 Jul 2020

30. Cycling New (2018) Television motorbikes are deciding races, says Lefevere. https://www.cyclingnews.com/news/television -motorbikes-are-deciding-races-says-lefevere/. Retrieved on 18 Jul 2020

31. Eindhoven University of Technology (2017) You Tube Channel; Wind tunnel movie: https://www.youtube.com/watch?v=VEDn IUJQfs

32. Barlow JB, Rae WH, Pope A (1999) Low-speed wind tunnel testing, 3rd edn. Wiley, New York

33. Franke J, Hirsch C, Jensen AG, Krüs HW, Schatzmann M, Westbury PS, Miles SD, Wisse JA, Wright NG (2004) Recommendations on the use of CFD in wind engineering. In: Proc. int. conf. urban wind engineering and building aerodynamics, (Ed. van Beeck JPAJ), COST Action C14, Impact of wind and storm on city life built environment. von Karman Institute, Sint-GenesiusRode, Belgium, 5-7 May 2004

34. Franke J, Hellsten A, Schlünzen H, Carissimo B (2007) Best practice guideline for the CFD simulation of flows in the urban environment, COST action 732

35. Tominaga Y, Mochida A, Yoshie R, Kataoka H, Nozu T, Yoshikawa M, Shirasawa T (2008) AIJ guidelines for practical applications of CFD to pedestrian wind environment around buildings. J Wind Eng Ind Aerodyn 96:1749-1761

36. Blocken B (2015) Computational fluid dynamics for urban physics: importance, scales, possibilities, limitations and ten tips and tricks towards accurate and reliable simulations. Build Environ 91:219-245

37. Malizia F, Blocken B (2020) CFD simulations of an isolated cycling spoked wheel: impact of the ground and wheel/ground modeling. Eur J Mech B Fluids 82:21-38
38. Casey M, Wintergerste T (2000) Best practice guidelines. ERCOFTAC special interest group on "Quality and Trust in Industrial CFD'. ERCOFTAC

39. Tucker P, Mosquera A (2001) NAFEMS introduction to grid and mesh generation for CFD. NAFEMS CFD Work. Group

40. Menter FR (1994) Two-equation eddy-viscosity turbulence models for engineering applications. AIAA J 32(8):1598-1605

41. ANSYS Inc (2015) Ansys fluent theory guide, Release 16.1, Canonsburg

42. ANSYS Inc (2019) Ansys fluent theory guide, Release 19.1, Canonsburg

43. Menter F, Egorov Y (2010) The scale-adaptive simulation method for unsteady turbulent flow predictions. Part 1: theory and model description. Flow Turb Combust 85:113-138

44. Blocken B (2018) LES over RANS in building simulation for outdoor and indoor applications: a foregone conclusion? Build Sim 11(5):821-870

45. Murakami S (1993) Comparison of various turbulence models applied to a bluff body. J Wind Eng Ind Aerodyn 46\&47:21-36

46. Tominaga Y, Mochida A, Murakami S, Sawaki S (2008) Comparison of various revised $\mathrm{k}-\varepsilon$ models and LES applied to flow around a high-rise building model with 1:1:2 shape placed within the surface boundary layer. J Wind Eng Ind Aerodyn 96(4):389-411

47. Martin JC, Milliken DL, Cobb JE, McFadden KL, Coggan AR (1998) Validation of a mathematical model for road cycling. J Appl Biomech 14:276-291

48. Gonzalez R (2019) The insane numbers behind cycling's most masochistic race. https://www.wired.com/story/cycling-hour-recor d-almost-impossible/. Retrieved on 18 Jul 2020

49. Wilson DG (2004) Bicycling science, 3rd edn. MIT Press, Cambridge

50. International Cycling Union (2019) UCI cycling regulations. Part 2: road raxces. Version July 2019. https://www.uci.org/inside-uci/ publications

Publisher's Note Springer Nature remains neutral with regard to jurisdictional claims in published maps and institutional affiliations. 